\title{
LA VERDAD COMO INSPIRACIÓN
}

Paloma García Briones*

¿Se puede pensar la verdad desde trascendentales antropológicos? Sí, se puede, y el resultado es una verdad que inspira, que refiere a un buscar no meramente lógico, sino libre, donde lo que se encuentra moviliza en lugar de extasiar en la contemplación sosegada; una verdad que no es fin, sino inicio. La inspiración es un momento propiamente significativo y caracterizador de la verdad: la verdad es esencialmente inspiración cuando se la observa en su ser algo propiamente humano.

\section{Palabras clave:}

Polo, Inspiración, Verdad, Trascendentales antropológicos

Can the truth be thought from anthropologic transcendental? It can, and the result is an inspiring true, that refers to a no merely logic searching, but free, where what is found mobilizes instead of to go into ecstasies in the calmed contemplation; a true that is not end, but beginning. Inspiration is a properly meaningful and characterizer of truth moment: the truth is essentially inspiration when it is observed in its being something properly human.

\section{Keywords:}

Polo, Inspiration, Truth, Anthropologic transcendental

\section{Índice de encabezados:}

1. Introducción.

2. Trascendentales metafísicos.

3. Trascendentales antropológicos.

4. La verdad como inspiración.

5. La libertad entendida desde el encuentro con la verdad.

6. Errores de Hegel y Descartes.

7. El sentido propio de la verdad.

*Universidad de Málaga. palomagbriones@hotmail.com 
8.Últimas consideraciones.

\section{Introducción}

Comenzaré esta exposición haciendo una introducción a lo que supone la filosofía de Polo. Y lo haré tomando como referencia un trabajo de Juan García titulado Las dualidades superiores de la persona, realizado a propósito de las II Conversaciones sobre la antropología trascendental de Leonardo Polo.

La filosofía de Polo es nuclearmente una antropología, y una antropología importantísima, porque modifica la índole misma del saber humano: lo amplía. Lo que se inicia en Polo es algo más que filosofía. Podríamos llamarlo "eleuterosofia": saber libre, y saber de libertad. O también "heurísticosofía": saber que se busca.

Ciencia que se busca es como denominó Aristóteles a la metafísica. Pero asociaba esta búsqueda con el deseo natural de saber. La filosofía primera era, pues, el anhelo dirigido hacia la teoría. Seguiría una dinámica tendencial, puesto que se desea lo que no se posee. El deseo se dirige al saber desde su ausencia.

En cambio, Polo, añade a la búsqueda de saber la noción de heurística. La búsqueda del saber no es una dinámica sólo desiderativa, sino cognoscitiva, plenamente compatible con la posesión de conocimientos, pues hasta se requiere saber para buscar. La búsqueda parte del saber con intención de saber más, de ir más allá de la teoría. Polo propone para esta nueva forma de saber un nuevo método: el abandono del límite mental.

De lo que se trata ahora es de ver en qué consiste todo esto de lo que vengo hablando. El mismo Polo dice que se trata de ampliar la metafísica clásica con una antropología trascendental.

Mientras que la metafísica es el estudio del ser fundamental, la antropología es el estudio del ser libre. Hay que distinguir entre el fundamento del mundo y el destino del hombre. El destino del hombre no deriva del fundamento, sino que remite a la libertad. Lo más característico de la persona es ser libre. Tras el abandono del límite, podemos hablar de "tiempo puro". El tiempo puro es el tránsito puro del antes al después. 
Según esto, el ser creado comienza en razón de su después o en pura dirección hacia él. Siempre se da una derivación del antes desde el después. La esencia deriva del acto de ser.

Pero la persona humana no es temporal; en su ser o realidad más íntima está por encima del tiempo. El ser personal está sobre el tiempo y tiene que ver con el tiempo en el modo de anteponerse a él. El valor de la libertad personal se cifra en la futuridad (tiempo humano en su vertiente trascendental). Es una posesión del futuro que no desfuturiza, una posesión del después como después. Se posee por cuanto la libertad está referida o abierta a ello (apertura).

El ser personal, o ser del mundo es comienzo persistente, mientras que la persona, más que comenzar está destinada. El disponer de tiempo es el modo de la reconducción de la esencia que se antepone respecto del ser personal.

La libertad no es sólo una propiedad de la conducta del hombre, de su voluntad, sino una característica de su ser. Con esto se empieza a entender que a los trascendentales metafísicos hay que añadirle unos trascendentales antropológicos.

\section{Trascendentales metafísicos}

Voy a recordar los trascendentales. La doctrina de los trascendentales es una doctrina propiamente medieval. Hay antecedentes en Platón y Aristóteles. Platón, en el Sofista habla de géneros supremos: notas de las cosas que desbordan la clasificación en géneros (lo mismo, lo otro, el movimiento, el reposo,...). Toda cosa es lo mismo que es. Y lo mismo pasa con el resto de géneros supremos. En Aristóteles, aparecen al final de las categorías los post predicamentales: nociones que desbordan las diez categorías, que son la sustancia y los nueve accidentes, por ejemplo, el movimiento, la anterioridad y posterioridad, etc. En ambos hay algo que desborda la clasificación en géneros y la clasificación en categorías. Lo trasciende.

En la filosofía medieval se supera la visión anterior con la distinción entre ser y esencia. El ser, la existencia, es lo que trasciende. Esto tiene consecuencias epistemológicas (con la inteligencia categorizamos, etiquetamos, mientras que hay una realidad detrás que desborda). Lo existencial es lo trascendental. 
El significado normal de lo trascendental es lo universalísimo, según la historia que acabamos de ver. Es lo que es más que general. Pero es una manera de entenderlo impropia. La universalidad no es lo característico de lo trascendental, sino la radicalidad, la profundidad, la ultimidad.

Lo que verdaderamente trasciende el plano de la categoría esencial es la existencia. Se trata de trascender sobre la conceptualización intelectual. Pero cuando se llega al punto de ver que lo trascendental es lo existencial, se supera su concepción de universalidad por la de radicalidad.

Riqueza interna del existir en tanto que equivalente al existir, eso es lo trascendental. De la existencia nace algo que es distinto que ella: lo esencial. Pero nace también algo equivalente: la verdad y la bondad. Los trascendentales, no es que sean universalísimos, sino que son propiedades internas a la existencia. La existencia se despliega en algo equivalente a ella que son los trascendentales.

La mejor clasificación de los trascendentales es la que hace Tomás de Aquino en la primera cuestión del De Veritate:

\begin{tabular}{|l|l|l|}
\hline ser & verdad & Bondad \\
\hline res (realidad) & algo & uno \\
\hline
\end{tabular}

También está la famosa cuestión de la belleza (pulchrum). Lo de la belleza no lo dice Santo Tomás en ningún sitio. Generalmente se consideran trascendentales la unidad, la bondad, la verdad y la belleza. Polo trata poco de la belleza. La define como capacidad de convocatoria. Y en su obra Quién es el hombre vincula la belleza, sobre todo, con el trascendental de la verdad: el aparecer en acontecimiento de la verdad está intrínsecamente unido a la belleza. La verdad es bella; la belleza es el esplendor mismo de la verdad. La admiración une la verdad y la belleza. Admiramos y la admiración nos anima a seguir profundizando en la verdad.

Aunque hay quienes no los admiten todos, el mismo Polo dijo en una ocasión que el dos era un trascendental. Juan García los reduce a ser, verdad y bondad. 


\section{Trascendentales antropológicos}

Pues bien, a estos trascendentales metafísicos, Polo añade los trascendentales antropológicos: el coexistir, el entender y el amar. O, dichos de otra manera: el coexistir, el intelecto personal, el amor donal y la libertad.

Ya introduje antes la consideración de la libertad como trascendental. Se distingue de la libertad como propiedad de la voluntad. Polo afirma además que pensar la libertad como un modo de actuar según motivos prevalentes no es del todo correcto. También se queda corta la concepción de la libertad como la interrupción del actuar. La libertad es más seria. Ni tampoco es cierta la visión de la libertad como arbitrariedad. Pero de esto hablaré más adelante, cuando se enriquezca su significado tras considerar la verdad como inspiración.

Podemos ver el caso del entendimiento. Es la persona la que ejerce el entendimiento, y no este último quien actúa por sí mismo. En la libertad de la actividad intelectual se manifiesta una peculiar forma de ser. La insistencia de la actividad intelectual indica un modo personal de mantenerse siendo. Ser además, persistir en vez de subsistir.

A partir de aquí paso a exponer la visión de Polo acerca de la verdad. Tras habernos introducido un poco en su antropología, se entiende fácilmente que para Polo la verdad sea inspiración.

\section{La verdad como inspiración}

Caer en la cuenta del encuentro con la verdad no es asunto de la inteligencia, sino que corre a cargo de la persona. La persona no se limita a entender, sino que está referida a la verdad de acuerdo con una búsqueda orientada al encuentro con ella. No cabe dirigir lógicamente esa búsqueda en tanto que llega a un encuentro que es imposible sin la libertad personal.

Una cosa es enterarse de algo y otra entender. Enterarse consiste en recibir una información que el entendimiento no llega a hacer suya. Entender implica ya una asimilación, una movilización de la inteligencia.

Pero la verdad es algo más que idea.

El encuentro con la verdad se transforma en un punto de partida. La verdad encontrada dispara un proceso interior porque es una 
fuente de inspiración que antes la persona no tenía. Encierra una novedad suficiente para que la conducta del sujeto arranque enteramente de este encuentro.

A esto lo llama Polo enamoramiento. El enamoramiento es la sustitución de la motivación por la verdad encontrada., de tal manera que comienzan a llevarse a cabo actos de homenaje a la verdad. Está más relacionado con la experiencia artística que con la deliberación, dominada por la razón práctica. Si el soporte de la deliberación es la motivación, el soporte de la inspiración es el encuentro con la verdad.

\section{La libertad entendida desde el encuentro con la verdad}

Ahora ya podemos hacer una consideración más profunda de la libertad, entendiéndola desde la antropología poliana y desde su concepción de la verdad.

- La libertad entendida como capacidad de obrar según motivos prevalentes no resulta bien pensada, porque el motivo está gobernado por lo que se intenta conseguir, que es algo distinto, de otro orden, que el propio motivo. En cambio, cuando se trata de una generación artística, su novedad, su valor respecto del antecedente, se encuentra en la obra hecha como desarrollo personal de la verdad encontrada. Al separarse de los motivos, por no necesitar obedecerlos, se da una sobreabundancia de libertad. No se trata sólo de buscar la verdad, sino de realizarse a partir de ella, de acuerdo con el carácter efusivo del ser humano y la índole donante o trascendental de la libertad.

- La libertad es más seria que una interrupción del actuar. No se pasa a otra cosa, sino a la actuosidad de la libertad. Una manifestación del carácter de acto de la libertad es la alegría del encuentro del hombre con la verdad. Encontrar la verdad no es terminal, sino que despierta una inspiración. Hay que hablar de gozo; una situación de sobreabundancia. No es algo necesitante. Lo que mueve en el encuentro con la verdad es la generosidad pura. La generosidad es coherente con la verdad encontrada, que merece el homenaje rendido por la persona (despliegue en el orden personal). Correspondencia con el exceso como superabundancia personal. No mera recuperación, inmanentización o complementación.

- Si se entiende la libertad como espontaneidad, a la fuerza la verdad se vuelve terminación. Si la verdad es el resultado de mi libertad, entonces la verdad se autodefine y se clausura. Pero la verdad no es lo 
último, ni lo primero, sino lo segundo. Podemos unir esto al trascendental de la coexistencia: la verdad no tiene un carácter terminativo, sino que adquiere una realidad oferente, donal, cuya consumación no es imposible si no existe otra persona.

La creatividad humana no se refiere a la verdad absoluta; y hay otras verdades orientadas a ella. No hay verdad sin camino y no hay verdad fuera de la vida. El camino es recorrido por la libertad con la verdad. La libertad equívoca o caprichosa carece de inspiración. Cuando sólo se admiten verdades pequeñas sin considerar la verdad trascendental, late el deseo de construir la propia vida con un alcance muy corto. Hay una limitación en el sentido de la libertad, una libertad desorientada.

En los hábitos reside el aprendizaje del control personal de la capacidad operativa.

Por el hecho de ser libres, podemos truncar la verdad. Por otro lado, el que asegure que la verdad no existe no es libre, porque la verdad sale al encuentro sólo al ser libre. En este sentido, dice Polo 'la verdad os hará libres'. La adecuación está, por tanto, trascendida. La libertad es condición previa para el encuentro con la verdad y al mismo tiempo se despliega con el encuentro con la verdad.

A priori la libertad no es arbitrariedad. Con la libertad tiene que ver el encuentro. Lo que se encuentra es la verdad. No una verdad desencarnada, o simplemente para pensar en ella. La verdad se yergue ante la propia vida, la impulsa; de esa verdad el hombre saca el impulso para su práctica. De la verdad depende enteramente el valor de lo práctico. Y sin verdad no hay libertad.

La verdad que uno se encuentra ha de ser una verdad amorosa. El que no sabe lo que es enamorarse, no sabe qué es la verdad. El hombre se puede enamorar de la realidad que sale a su encuentro de un modo radiante, hasta embarcar su ser en ella. Eso es ser libre destinándose.

Si el acontecimiento de la verdad no tiene lugar en la vida del hombre, su vida será anodina, no podrá ser libre. La verdad es el valor supremo, aquello con lo que se conecta la libertad y sin lo cual la libertad no puede ser intensa. Seguramente la verdad más radical que el hombre puede encontrar en esta vida es la verdad personal. 


\section{Errores de Descartes y Hegel}

Hemos visto que si la libertad se entiende como espontaneidad, la verdad es su formalización o determinación terminal. La verdad entendida a modo moderno elimina la inspiración. La libertad de la persona se añade a la verdad (carácter de además). Es distinta de la libertad como propiedad de la voluntad. La propia conducta se eleva entonces a manifestación, a canto a la verdad, a símbolo. Vemos aquí un distanciamiento con Descartes. La consecuencia de la perspectiva subjetivo-objetualista derivada del afán de certeza cartesiano es que ante la verdad sólo quepa detenerse. El error está en partir para la filosofía de la paralización de la verdad para aquietar la sospecha y la duda. La verdad está destinada a movilizar.

Esta nueva manera de pensar la verdad no sólo supera el racionalismo. En efecto, Polo se opone también al idealismo. El idealismo se podría definir como la filosofía del primado de la verdad entre todos los trascendentales. Pero esto supone no dar cabida al resto (al ser y a la bondad), además de no considerar los antropológicos. Hegel decía: "La lechuza de Minerva levanta el vuelo al atardecer". Pero la verdad no es un simple espectáculo, así que no nos limitamos a asistir a su aparición. Lo que hacemos es integrarla, asimilación que pone el ser personal. Aquí es donde se encuentra, para Polo, el error de Hegel. Hegel aspira a una especie de contemplación terminativa de la verdad y sienta una equivalencia de la verdad con su contemplación especulativa. Se queda corto, pues la verdad no es lo primero ni lo último.

\section{El sentido propio de la verdad}

Es una manera de ver la verdad no como trascendental metafísico, sino trascendida, de acuerdo con los trascendentales antropológicos. No adecuación, sino expansión. Se transforma en uno mismo y va más allá de la verdad formalmente considerada. El tercer estatuto de la verdad según Tomás de Aquino.

Él distinguía tres sentidos en los que se habla de verdad:

-Verdad ontológica. La verdad considerada como trascendental, como propiedad de todo lo que es en cuanto que es.

-Verdad lógica. Es el sentido propio de la verdad. Consiste en la adecuación entre la inteligencia y la realidad. 
-Verdad en el lenguaje, que es la transmisión de esa adecuación. Éste es el sentido que amplía Polo.

Además de los sentidos ontológico y lógico de la verdad, hay un sentido post racional, más allá de lo racional, porque se añade a lo racional. Las obras tienen valor simbólico porque la verdad no puede ser expresada enteramente. El despliegue de las actividades inspiradas no es enteramente realizador. Además, la verdad que sale al encuentro no es la verdad entera. Símbolo: remitir a una verdad que todavía no ha salido al encuentro desde otra no operada por completo.

La verdad formal no es el sentido más amplio de la verdad, puesto que la verdad lógica no inspira. El sentido formal establece su estatuto en el conocimiento, pero que la verdad sea encontrada es algo más que el hecho de que sea conocida, y ese 'más' implica la libertad. Para la libertad la verdad es inspiración.

Para un sujeto libre la verdad no es descender desde ella hasta sus aplicaciones (verdad de la ciencia), sino ascender a la verdad cantada. El canto es la audición de la verdad de acuerdo con la propia entraña. Y sólo un ser personal es capaz de ello. En la verdad todo el hombre retiembla. En la persona, la verdad y el amor están unidos antes de su distinción en operaciones de facultades distintas. La verdad en el hombre es indisolublemente amor, superabundancia, en lugar de un remedio necesitado. Lo dice Rilke: 'el hombre está más allá de todo fin'. No se puede decir que lo que sigue a la verdad no sea verdad.

\section{8. Últimas consideraciones}

Según todo esto, se pueden hacer unas últimas consideraciones, pensando en las consecuencias, en lo que deriva de esta concepción de la verdad.

La primera de ellas es una reflexión sobre el mal. El mal es la falta de inspiración, pues la libertad en el acto malo no añade nada, sino que sucumbe en él. El mal no inspira, no es generativo y lleva al pesimismo, pues se oscurece la mirada. La señal de la verdad es la alegría (luz de la mirada). La alegría es una añadidura que el hombre pone en su encuentro con la verdad. Y la inspiración libre es generativa.

El dolor como tal carece de sentido, por lo que constituye un obstáculo al encuentro con la verdad, un muro infranqueable a la libertad. Como mucho, puede ser aprovechado como un factor para la maduración 
del hombre, pero no puede ser atravesado ni ser un camino para trascendencia.

Cuando el tiempo se vive desde la tristeza, el propio vivir está disminuido. La tristeza es directamente contraria a la expansión de la actividad, no se crea. Es inmovilización del curso de la existencia, encapotamiento del futuro. En cambio, la esperanza forma parte de la libertad debido a su conexión con la verdad. Sacar a la luz los implícitos de la verdad se convierte en un modo de existir, es vivir de acuerdo con la verdad.

Por último, añado unas palabras de Luigi Pareyson: "Conocer y poseer la verdad no es posible sin comprometerse, sin tomar partido, sin exponerse personalmente; y esto no sucede sólo en la filosofía entendida como formulación de la verdad, sino en cualquier interpretación que sea digna de este nombre por mínima e insignificante que parezca". ${ }^{1}$ La vida es buscar la verdad y realizarse a partir de ella, de acuerdo con el carácter efusivo del ser humano y la índole donante o trascendental de la libertad.

Paloma García Briones es estudiante de licenciatura del departamento de filosofía de la Universidad de Málaga.

Este trabajo, la verdad como inspiración, reproduce la ponencia de Paloma García del 6 de abril de 2010, en el centro cultural Vicente Aleixandre, Alhaurín de la Torre (Málaga), y que supuso el acto final con el que se cerró el ciclo de seminarios en torno a la verdad organizados por Claridades. Revista de filosofía en colaboración con el área de filosofía del departamento de filosofía de la Universidad de Málaga.

\footnotetext{
${ }^{1}$ Luigi Pareyson, Veritá e interpretazione. Mursia, Milano, 1982, pg. 86
} 